\title{
Behind The Scenes: The 5 "W's" Of Administering A College Of Business Professional Enrichment Program
}

Elizabeth C. Ekmekjian, William Paterson University

\begin{abstract}
What can we do as college administrators and faculty to better prepare tomorrow's young professionals? How does one create a program to satisfy this objective? This paper will address how the William Paterson University (WPU), Christos M. Cotsakos College of Business (CCOB) created a unique and innovative program designed to enhance a student's education by offering workshops and seminars focused on career development, ethics, leadership and numerous other life skills. The who, what, where, how, when and why of administering this program will be provided. Particular emphasis will be placed on the numerous goals and hurdles in a college setting such as: community and alumni involvement; reporting requirements (attendance and assessment); budget concerns; student awareness; advertising; and faculty support.
\end{abstract}

\section{INTRODUCTION}

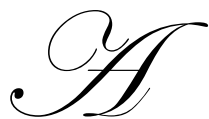

recent newspaper article reported that colleges and employers aren't always on the same page. When it comes to matching skills sets desired by employers and what colleges are doing to prepare tomorrow's professionals, there is often a disconnect. The column discusses the findings of a report published in the fall 2004 journal of the National Association of Colleges and Employers, NACE. In this report, Michigan State University researchers concluded that employers surveyed rank skills such as communication, adaptability and life skills higher than schools.

Based on similar statements and recommendations received from its' stakeholders, in Fall 2002 the William Paterson University of New Jersey (WPU), Christos M. Cotsakos College of Business (CCOB), implemented a Professional Enrichment Program. This initiative would assist in bridging the gap between colleges and employers by offering workshops and seminars focused on career development, ethics, leadership and numerous other life skills.

The Professional Enrichment Program has received overwhelming praise by students and staff of WPU, as well as commendations from alumni and other valued stakeholders. The Association to Advance Collegiate Schools of Business (AACSB) cited the Program as, "a commendation of strength, innovation and unique features, as well as an effective practice," in their evaluation report of the CCOB in October 2004.

\section{WHO?}

Founded in 1855, WPU is an institution of higher education of the State of New Jersey. While the University is celebrating its' $150^{\text {th }}$ anniversary, the emphasis on a business curriculum has been in place for just over 25 years and is housed in the CCOB. In January 2005, the CCOB received its' most prestigious accolade to date, accreditation by the AACSB! As the director of the Professional Enrichment Program, I am honored to say that the Program was one of several strengths that led to this accreditation. 


\section{WHAT IS PROFESSIONAL ENRICHMENT?}

The program is designed to enhance a student's college education by providing opportunities to meet and network with area specialists, hear business leaders speak, become involved in work related activities such as internships, practicum, and job shadowing, and attend various seminars and forums that deal with professional development and/or contemporary work related issues.

\section{WHERE?}

The CCOB is nestled in the heart of Wayne, New Jersey - home to hundreds of businesses and a number of corporate headquarters. Our location provides a distinct advantage in that it allows us to procure the services of myriad guest lecturers from these entities.

\section{HOW AND WHEN?}

\section{Program Inception}

During the summer of 2002, the Dean of the CCOB provided me with a concept, student requirements and some thoughts on how to get started. The concept was simple; the CCOB was to offer workshops that would help prepare students for life in the real world. These workshops would be required of all students. Adding a college course to the current curriculum would be extremely difficult. Accordingly, another alternative was sought to give the program some strength. The course leader for an upper level core course (required of all students) agreed to incorporate a PE requirement into the Business Strategy and Policy course. (A course leader is responsible for preparation of a course outline. The outline provides all instructors who teach the course, what materials are to be covered and all requirements.) Ten percent of a student's grade earned in the course would be a function of the number of enrichment points earned: four points (eight activities) are required to earn full credit. This attendance policy was cumulative in nature whereby students could earn points during their tenure at WPU. The Dean suggested establishing an attendance database which would be updated via scanning of student ID cards.

Aimed with an innovative idea and student requirements, the Dean and I discussed the types of activities to be offered. The first semester would kick-off with a focus on career development, communication skills and relationship building. Assistance in offering these activities would come primarily from the University's own resources. I was provided with contact information for the WPU Career Development Center and Alumni Relations department, and given a last bit of advice: establish relationships with University personnel, our alumni and the community, and ensure that these relationships are mutually beneficial.

\section{Career Development Center}

With this key advice in mind, I met with the Career Development Center staff and explained my objective in offering valuable workshops to our students while, in turn, promoting the services of the Center. Despite the fact that I just increased their work load significantly, I think it is safe to say that they were excited about the program and enthusiastic to become a part thereof. It is important to note that the Center's staff saw the Professional Enrichment Program as an opportunity to further assist WPU's students and promote these valuable resources.

We settled on a number of activities including: resume writing; internship orientation; interview strategies; job searching and networking opportunities; and a "careers in" series. The Center had numerous contacts with valuable stakeholders such as alumni, local businesses and groups such as the Chamber of Commerce. Outreach for volunteer guest speakers would be organized and initiated through the Center.

The next step was scheduling. In the past, I had attended student workshops and was disappointed to see the low number of student attendees. All parties mutually agreed that if we were going to reach out to our stakeholders and ask them to volunteer their time to speak with our students, we did not want to have low student turn out, but wanted to guarantee a good audience. In order to accomplish this, I sought the support of my fellow 
faculty members and asked them to "host" these workshops. My definition of "host" is to hold the activity on the time/day of a class and prepare the students for a guest speaker. This method of hosting workshops satisfied two purposes: (1) students were introduced to the Professional Enrichment Program and activities - hopefully encouraging their attendance at future events; and (2) student attendance increased significantly and typically averaged approximately 30 students per event.

Thus, a system was established whereby the Center and I would select the activities to be offered, I would handle scheduling and advertisement of the event (promoting the Career Development Center), and they accepted responsibility for organizing and hosting the event. This turned out to be a great help and an absolute necessity as you will see that administering a successful program is time intensive.

\section{Alumni Relations}

one another.

Next, I met with two more of the University's administrative staff in an effort to see how we might help Through meetings and discussions with our Alumni Relations department, we determined that the Professional Enrichment Program would provide a terrific opportunity to invite our alumni back, show them how the University has grown and changed, and offer them a chance to meet with/speak to our students. So many are anxious to give back to their alma mater; this is a great way to get involved. Accordingly, I discussed the activities that I was hoping to offer and we tried to find a fit for alumni involvement. These efforts were also coordinated with the Career Development Center.

\section{More Networking}

I soon found out that my responsibilities would require me to meet with a number of people in order to offer a successful program. Additional relationships were established with faculty, the University's Small Business Development Center, MBA Program director, e*Trade Financial Learning Center, marketing and public relations department. Each contributed by offering workshops and/or assisting with scheduling and marketing events.

\section{Initial Activities}

By September 2002, a small one page brochure was prepared and distributed to students and faculty announcing the new program. The Fall 2002 activities included twenty plus workshops such as: resume writing, internship orientation, interview strategies, job searching and networking opportunities, "careers in" series, planning for an MBA, women in business seminar, toastmasters' demonstration meeting, "meet the professor" series, annual stakeholders conference, accountants, bankers \& lawyers networking breakfast, professionally qualified symposium and presentation skills. The Spring 2003 calendar added a student orientation, case study analysis, business leaders' symposium, library skills workshops, business etiquette, job fair preparation, job shadowing day, crisis management workshop and the New York Stock Exchange and Federal Reserve field trip. Only the "meet the professor" series was cancelled.

\section{Attendance, Outcomes Assessment And Assistance}

At each activity, several items need to be taken care of. First, an attendance sheet and outcomes assessment form need to be prepared. An attendant needs to be present to take attendance, collect student ID cards, copy the ID cards, pass out and then collect the outcomes assessment forms. The ID cards are copied as we soon learned that it was easier to read the ID cards vs. the hand-written scrawls on the attendance sheets. The attendance sheets, copies of ID cards, contact information for each speaker and handout materials are filed in an event folder. As you can see by the time consuming nature of these items, the use of an assistant or graduate student is vital to perform all of the above tasks. 


\section{Year One Attendance Nightmare}

The 2002-2003 academic year's attendance was rather impressive totaling 1,568 students. While I am able to boast of the attendance numbers, I now share with you my nightmares. You will recall that the Dean suggested utilizing a scanning system for attendance. Unfortunately, this system was unable to be implemented until the second year of the program. This meant that all attendance record keeping was to be performed manually (and primarily by me)! The Associate Dean was able to download a list of CCOB students and identification numbers. This information was incorporated into an excel spreadsheet. Each of the approximately sixty events offered during the academic year were listed in columns across the top of the sheet and student attendance was marked event by event off of attendance sheets.

A copy of the spread sheet was provided to all CCOB faculty members. In addition, an additional administrative burden existed. All Business Strategy and Policy faculty needed to determine whether their students satisfied the four point requirement. Accordingly, course lists were obtained from the faculty and points were calculated for each student. This information was prepared for and provided to the faculty members.

\section{Moving Forward - Years Two And Three}

The Professional Enrichment Program grew in leaps and bounds whereby approximately one hundred events are offered each semester. Additional events include: time management skills, sexual assault awareness, public speaking skills, library business research workshops, international business practices, mock interview sessions, golf etiquette, ethics, credit management, small business development and career fair preparation - to name a few! In addition, students are able to earn PE points by participating in activities offered by the WPU Career Development Center (such as one-on-one resume writing or interviewing skills sessions); the WPU Small Business Development Center (which offers strategic assistance to entrepreneurs); the WPU E*Trade Financial Learning Center (an advanced, simulated electronic trading room which offers workshops concerning the principles of investing and money management); and the WPU Instruction and Research Technology Office (which offers computer skills workshops on current software applications such as Microsoft Word® and Microsoft Excel®).

\section{Trials And Tribulations}

\section{Record-Keeping Progress}

Attendance - The scanners arrived just in time for the Fall 2003 semester. Manual data entry was replaced with the following process: student ID cards were scanned; the scanners were downloaded and student information entered into an excel spreadsheet. Unfortunately, the scanners are not one hundred percent. Periodically, student information is not read by the scanner. This requires a double check of the attendance sheets/copies of ID cards, with the download. A separate attendance database was created for each of the last four semesters.

The scanner problem is not the sole record-keeping dilemma. Due to the cumulative nature of the PE point requirement for Business Strategy and Policy, attendance records must be maintained and referred to for a number of years. For example, if a non-traditional student takes 1-2 courses per semester, we may need to look back several years in order to accumulate PE points. In addition, students are constantly checking on their point totals. These requests are to be sent to a separate e-mail address which is maintained by my assistant, however, most requests come to me which I must then forward. These processes are extremely time consuming. If there were a way to post students' point totals, both problems would be eliminated; I am still searching for a solution.

Assessment - At each event, a survey of outcomes assessment questions is distributed to each student. The results are tabulated by the Office of the Associate Dean and presented annually by the CCOB's Outcomes Assessment Committee. This information is used to improve workshops and types of offerings. 


\section{Budget, Volunteer Presenters, And Mutually Beneficial Relationships}

As in all academic institutions, funds are tight. I am afforded a minimal budget which pays primarily for a part-time assistant, scanners, food and refreshments for certain events, printing costs, postage, gifts and other supplies. Typically, I spend less than $\$ 1,000$ per semester on speakers.

I am happy to report that with very few exceptions, our workshops are given by volunteers. People are amazed that I am able to offer one hundred events with paying our presenters. We are fortunate to have so many wonderful people (faculty, staff, alumni and area business leaders), who are willing to give of their time. In return, we send thank you notes with a small gift.

In addition, kindly recall that the Dean offered the advice that we should offer mutually beneficial relationships. With each of our speakers, we hope to be able to provide some service or opportunity. University departments receive advertising in the form of our activities calendars (issued each semester and available on-line); and alumni and area business leaders are encouraged to see how the University can help them (perhaps by utilizing our library, providing sources for internships and other employment opportunities, etc.).

\section{Program Awareness}

Promoting the program has proved to be rather difficult. During the first semester, faculty members teaching Business Strategy and Policy advised their students of the PE requirement and informed them how to satisfy it. A few other faculty members assisted in these efforts by informing their students. Brochures were made available in all CCOB departments; events were posted on billboards and advertised on plasma screens in the CCOB building. These efforts were insufficient, however, as the majority of students were unaware of the program and its requirements.

In an effort to increase program awareness, the following steps have subsequently been taken:

- $\quad$ classroom visits were made by the Dean and myself;

- $\quad$ faculty were encouraged to introduce the program to students and hand out brochures;

- $\quad$ the Activities Calendars were made available on-line;

- $\quad$ student orientation sessions were held;

- $\quad$ presentations were made at University freshmen orientations; and

- $\quad$ a notation was made on the degree audit (audit sheet listing University requirements for graduation) of all CCOB students.

This last item seems to have had a significant effect as a number of students are now inquiring about the program.

\section{Advertising}

As previously mentioned, at the start of our first semester, a one-page brochure was prepared and distributed to faculty and students. Its content included a description of the program, requirements and information concerning earning PE points. Events were categorized by sponsor and listed with no descriptions provided. The Spring 2003 Schedule of Events listed the activities in chronological order and provided brief descriptions of each workshop. These first brochures led me to the Marketing and Public Relations department of the University - which was a great move!

We wowed them in the Fall 2003 semester with a glossy six part brochure. This $8 \frac{1 / 2}{2} 11$ Activities Calendar was eye catchy and a document that would receive respect and awe. Workshop descriptions were more refined and organization of the content was very professional. A few additional refinements were recently made and appear in the eighteen page Fall 2005 Activities Calendar. First, the program information now appears in the form of a FAQ - frequently asked questions - and is easier to navigate. Next, the Calendar provides both an alphabetical 
listing of activities (categorized by type of event, such as Career Advancement, Professional Business Practices and Leadership Skills, Personal Finance), and a chronological listing.

The reward is not without much sweat, however. Following is a list of items which require significant attention.

- $\quad$ Activities must be organized so that both day and night students are availed an opportunity to attend.

- $\quad$ Events need to be run each day of the week (although we have excluded Saturdays anticipating lack of attendance).

- $\quad$ Run-around time must be incorporated to speak with numerous professors requesting that they host certain workshops.

- $\quad$ For activities that are not hosted, reserving rooms is often difficult due to lack of available space.

- Classroom size is also at issue as rooms accommodate anywhere from twenty to one hundred seventy-five students (making some rooms too small and others too large). I find that the appearance of a full house is better than using an auditorium that is only half full.

- Once I have completed a draft calendar, it is then sent to the WPU Marketing and Public Relations department, the brains behind the eye-catchy brochures. My information is put into the proper form and then forwarded to me for review. Typically, we go back and forth for three weeks with changes, modifications, etc., before the file is ready to go to the printer. Printing takes another two weeks. This lengthy time line requires me to submit my material five to six weeks before each semester in order to have the Calendars back from the printer in time for school.

- This may not appear to be problematic for the fall semester; however, communicating with faculty and staff is often difficult because of vacations and the fact that the University is closed on Fridays during the summer months.

- The spring semester is even worse, however, as my primary concern is teaching and I must prepare and grade final exams and submit grades. Combining my academic responsibilities with the Professional Enrichment administrative duties requires a bit of juggling and organization.

Following is a link to the Professional Enrichment page;

http://www.wpunj.edu/cob/COB new/professionalenrichment/profenrich.htm . From here you can click on each of the past seven semesters for a view of our calendars.

\section{Faculty Buy-In}

I believe that the vast majority of CCOB faculty members consider the Professional Enrichment Program to be a terrific addition to our students' education. In fact, a number of professors have implemented a per-semester point requirement ranging from allowing extra credit for attendance at events, to adding points to exam grades, to requiring attendance at $\mathrm{x}$ number of events evidenced by a write-up of the activity. However, faculty buy-in is not one hundred percent. The most popular complaint is that these activities should not be offered in the class-room. To this, I can only encourage these faculty to inform the students of the PE point requirement and promote activities that they believe in. After all, everyone is entitled to their opinion and we can agree to disagree.

\section{WHY? AND CONCLUSION}

As previously discussed, the Professional Enrichment Program was implemented in response to comments from valued stakeholders concerning preparing students for life after WPU. We believe that the Program contributes to student success and that it will add to our quest to become a premier business school. This opinion was shared by the

AACSB as they cited the Professional Enrichment Program as "a commendation of strength, innovation and unique features, as well as an effective practice," in their evaluation report of the CCOB (Oct. 2004). 
The Program also adds value to the University and its commitment to the WPU students, alumni and the community. We have successfully promoted services that the University offers, such as the Career Development Center, Counseling, Health and Wellness Center (which offers workshops such as Stress Management and Time Management), the Institute for Creative Aging, Students of Life Program (offering personal financial and money management skills activities), and Instruction and Research Technology (providing group and one-on-one instruction on current software applications). Relationships with alumni and local businesses have been established or re-established and maintained as guest lecturers are sought from this valuable pool of contacts. Community involvement has increased through networking and sponsorship of events by the local Tri-County Chamber of Commerce, local chapter of the New Jersey Societies of Certified Public Accountants, and area businesses.

In conclusion, with a significant amount of assistance from staff, faculty, alumni and other valued stakeholders, the Program has expanded from twenty initial activity offerings to more than one hundred events per semester; attendance from inception through Spring 2005 totals more than eight thousand students. While we've had to jump through hoops and hurdles, and are still addressing administrative issues, assessment of the program indicates that it is a success and one that can serve as a model for other similar programs.

\section{NOTES}


Journal of Business Case Studies - March 2008

Volume 4, Number 3

NOTES 